\title{
Aza-Diels-Alder versus 1,3-Dipolar Cycloadditions of Methyl Glyoxylate Oxime with Cyclopentadiene
}

Carlos A. D. Sousa, ${ }^{a}$ M. Luísa C. Vale, ${ }^{a}$ José E. Rodríguez-Borges ${ }^{\mathrm{a},{ }^{*}}$ and Xerardo GarcíaMera $^{b}$

${ }^{a}$ CIQ-Departamento de Química, Faculdade de Ciências, Universidade do Porto, Rua do Campo Alegre, 687, 4169-007 Porto, Portugal. 'bepartamento de Química Orgánica, Faculdade de Farmacia, Universidade de Santiago de Compostela, E-15782 Santiago de Compostela, Spain

\footnotetext{
Abstract - The acid-catalyzed [3+2] and [4+2] cycloadditions between methyl glyoxylate oxime (1) and cyclopentadiene were investigated using various Lewis and/or Bronsted acids at different temperatures in dichloromethane as solvent. Besides the expected new adducts, $( \pm)$-methyl [(3exo)-2-hydroxy-2-azabicyclo[2.2.1]hept-5-ene]-3-carboxylate (2) and (士)-methyl [(3-endo)-2hydroxy-2-azabicyclo[2.2.1]hept-5-ene]-3-carboxylate (3) a third adduct, ( \pm )-methyl $(1 R, 4 R, 5 R)$ (2-ox-3-azabicyclo[3.3.0]oct-7-ene)-4-carboxylate (4), whose formation can be explained by a concerted 1,3-dipolar cycloaddition, was obtained. Yields and product ratios were found to be more dependent on the catalyst than on the temperature; these results and the stereochemistry of the adducts, confirmed by spectroscopic data ( ${ }^{1} \mathrm{H}$ and $\left.{ }^{13} \mathrm{C} \mathrm{NMR}\right)$ and by X-ray crystallography, were used to analyze and propose a mechanistic explanation for both $\left[\pi 4_{s}+\pi 2_{s}\right]$ cycloadditions.
}

\footnotetext{
* Keywords: aza-Diels-Alder reaction, 1,3-dipolar cycloaddition, glyoxylate oxime, isoxazolidines, 2hydroxy-2-azabicyclo[2.2.1]heptenes

Corresponding author. Fax: +351-226082959. e-mail: jrborges@fc.up.pt (J.E. Rodriguez-Borges).
} 


\section{Introduction}

The great versatility of cycloadditions, their high stereochemical control and the fair predictability of their regiochemistry allied to the rapid accumulation of polyfunctionality in a relatively small molecular framework, have contributed to the popularity of these reactions. ${ }^{1}$ Within the diverse transformations comprising cycloadditions, aza-Diels-Alder reactions of imine derivatives and dienes leading to six-membered aza-heterocycles, monocyclic and bicyclic molecules, have attracted much interest, especially those employing cyclopentadiene as starting material. $^{2,3}$ The imines, used as aza-dienophiles, generally require activation by an electronwithdrawing group and a Lewis acid (LA) and/or Bronsted acid (BA) to participate in these [4+2] cycloaddition reactions. ${ }^{3}$ It has been shown that the electronic nature of the substituents at the diene/dienophile pair may strongly influence the reaction pathways and determine either a concerted mechanism (synchronous or asynchronous) or a stepwise one ${ }^{4}$. In addition, experimentalists have always employed catalysts to change the kinetics of this class of reactions. In particular, a wide range of homogeneous and heterogeneous Lewis acids have been used to improve the rate and exo/endo selectivities of these cycloadditions. ${ }^{2,3}$

Reports on cycloadditions between iminodienophiles of glyoxylates and cyclopentadiene showed these reactions to be highly accelerated by the addition of a LA, due to the formation of an iminium cation complex that rapidly undergoes cycloaddition under mild conditions. The products obtained, 2-azabicyclo[2.2.1] hept-5-enes, ${ }^{3}$ can be used as precursors of a large variety of compounds of chemical, biological and pharmaceutical interest, such as proline mimetic structures. ${ }^{5} \mathrm{~N}$-hydroxylimines (oximes) bearing electron-withdrawing groups, on both carbon and oxygen, have been used upon occasion as imino dienophiles. ${ }^{6}$ Fleury and coworkers investigated cycloadditions of $O$-protected oxime derivatives $(\mathrm{XYC}=\mathrm{NOR})$ with cyclopentadiene to afford the corresponding adducts with low to moderate yields. ${ }^{\text {aa-c }}$. Nonetheless, aza-Diels-Alder reactions using non- $O$-functionalized oximes have never been reported in literature, resulting in an unknown behavior of the hydroxyl group bound to the nitrogen atom. The resulting $N$-hydroxyl2-azabicycloalkenes would be an important and versatile group of synthons useful in the preparation of new pyrrolidinic derivatives. ${ }^{5}$

It is well known that LA often increase not only the rate of the Diels-Alder reactions but also their selectivity. Thus, we decided to investigate, in this work, the influence of several LA and their advantages/disadvantages relatively to $\mathrm{BA}$ in the aza-Diels-Alder reaction between 
cyclopentadiene and methyl glyoxylate oxime (1) to afford the corresponding exolendo adducts (Scheme 1).

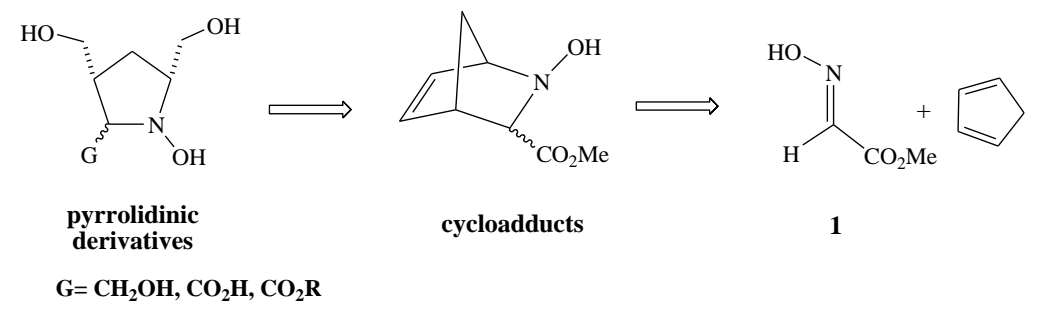

Scheme 1. Retrosynthetic analysis of pyrrolidinic derivatives from cycloadductos of glyoxylate oxime $\mathbf{1}$ and cyclopentadiene

\section{Results and discussion}

Methyl glyoxylate oxime $(\mathbf{1})^{8 a}$ was obtained by treatment of methyl 2-hydroxy-2methoxyacetate (methyl hemiacetal of methyl glyoxylate) ${ }^{7}$ with equimolar amounts of hydroxylamine hydrochloride, triethylamine and a catalytic amount of DMAP, in dry $\mathrm{CH}_{2} \mathrm{Cl}_{2}$ at room temperature. ${ }^{8}$ The $E$-configuration of oxime $\mathbf{1}$ has been unambiguously assigned by X-ray crystallography (Figure 1).

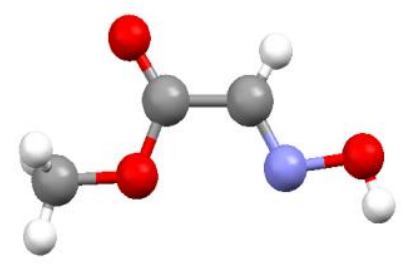

Figure 1. X-ray crystallographic structure of oxime 1

Treatment of oxime 1 with freshly distilled cyclopentadiene (2 eq.) and acid (TFA, $\mathrm{BF}_{3} . \mathrm{Et}_{2} \mathrm{O}, \mathrm{AlCl}_{3}, \mathrm{ZnI}_{2}$ or $\left.\mathrm{HClO}_{4}\right)$ in $\mathrm{CH}_{2} \mathrm{Cl}_{2}$ under an argon atmosphere at different temperatures $\left(-78^{\circ} \mathrm{C},-20^{\circ} \mathrm{C}\right.$ and $-12^{\circ} \mathrm{C}$ ) yielded the corresponding cycloadducts 2 and $\mathbf{3}$ (aza-Diels-Alder reaction). A third adduct (4) was also obtained, probably via a 1,3-dipolar cycloaddition (Scheme 2). 

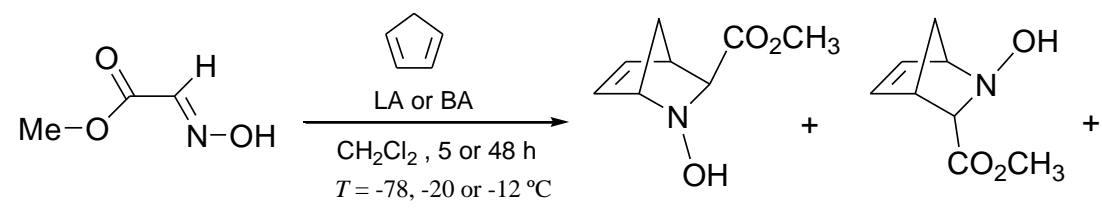

$( \pm)-2$ - exo

$( \pm)-3$ - endo
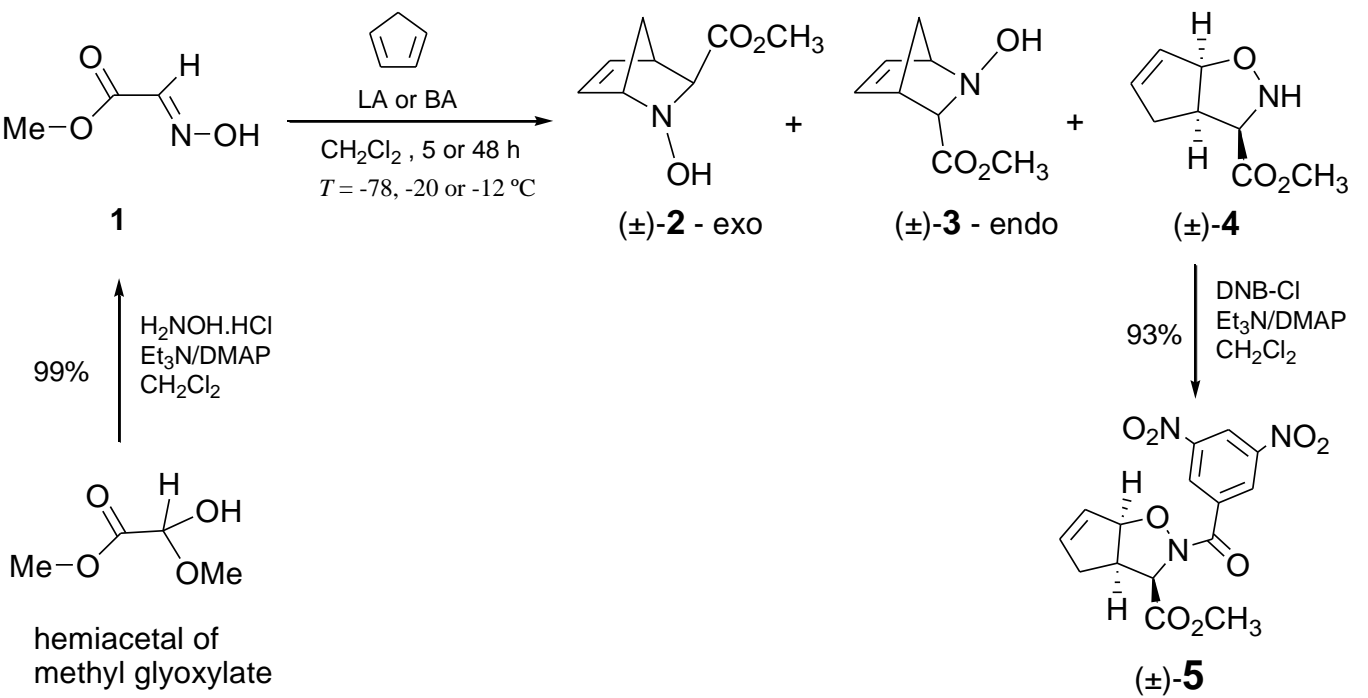

$( \pm)-5$

Scheme 2. Products of cycloaddition between oxime 1 and CPD and 3,5-dinitrobenzoyl derivative of adduct 4.

The products were isolated from the reaction mixture by chromatographic purification and identified by analytical and spectroscopic techniques. ${ }^{9}$ Thus, the endo-configuration of cycloadduct 3 has been confirmed by X-ray crystallography (Figure 2).

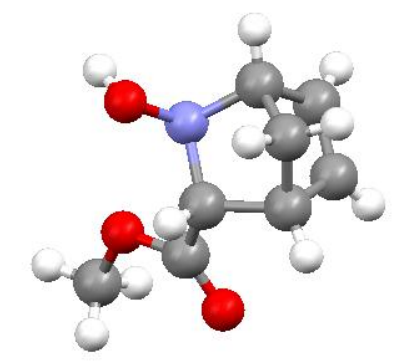

Figure 2. X-ray crystallographic structure of endo adduct 3

The structure and stereochemistry of cycloadduct $\mathbf{4}$ were established not only in terms of its spectral data, but also based on the spectral data and X-ray diffraction studies of the corresponding 3,5-dinitrobenzoate derivative ( \pm )-5 (Figure 3). Furthermore, the ratio of adducts obtained, for each reaction, was also confirmed by GC (Table 1). 


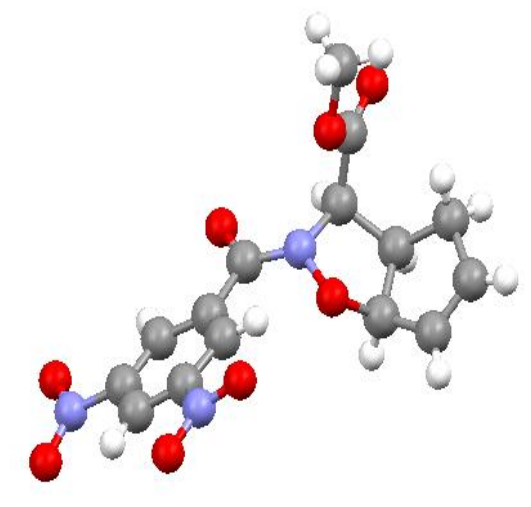

Figure 3. X-ray crystallographic structure of compound 5

Checking the literature for 1,3 -dipolar cycloadditions, ${ }^{10}$ there are some reports on oximes undergoing 1,3-dipolar cycloadditions via the nitrone tautomer with alkenes (dipolarophiles) to afford isoxazolidines. ${ }^{10 i-k}$ The presence of a nitrogen atom within the isoxazolidine ring makes this heterocyclic moiety especially attractive for the synthesis of a number of alkaloids, and other nitrogen-containing natural products, and many products of potential interest. ${ }^{10}$

Concerning the effect of temperature on product ratio and yield, when Lewis acids were used as catalysts, little or no change was observed when the temperature was raised from $-78^{\circ} \mathrm{C}$ to -12 ${ }^{\circ} \mathrm{C}$. With TFA, a significant modification in both, ratio of $\mathbf{2 / 4}$ and product yield occurred. When the reaction was performed at $-20{ }^{\circ} \mathrm{C}$ during 48 hours, and/or using excess of acid (2 eq.), a decrease in the yield was verified (all these experiments resulted in the formation of a large amount of a polymer, which may indicate some degradation of the products). However, in the cases where Lewis acids were used, the ratios of $\mathbf{2 / 3 / 4}$ remained unaltered, whereas the use of TFA and $\mathrm{HClO}_{4}$ lead to a significant change in the ratio of $\mathbf{2 / 4}$. Moreover, when these Bronsted acids were employed, the ratios of adducts (mainly $\mathbf{2}$ /4) depended on the experimental conditions, in a way that is not yet fully understood and is under further investigation.

In order to confirm whether adduct 4 resulted from Meisenheimer rearrangement ${ }^{11}$ of $\mathbf{2}$ or $\mathbf{3}$ or was formed via an independent pathway, these adducts ( $\mathbf{2}$ and $\mathbf{3}$ ) were subjected to the same reaction conditions of the cycloaddition (except CPD) during 5 hours. No trace of 4 was detected in the reaction mixture, thus confirming the independent pathway hypothesis.

Generally, most oximes will undergo the normal Beckmann rearrangement in the presence of certain acids, including Lewis acids, or under neutral conditions to yield an amide or a mixture of amides, and a wide variety of examples are listed in reviews. ${ }^{12}$ When we performed the referred 
cycloaddition reactions, we were not able to isolate (or detect) any amide or nitrile or their adduct derivatives. This may be due to the syn geometry of the hydrogen atom ( $E$-oxime) which does not allow the occurrence of the referred rearrangement; on the other hand, oxime isomerization is not probable at low temperatures.

Table 1. Cycloaddition reactions of cyclopentadiene (2 eq.) with oxime 1. Yield (\%) and ratio (\%) of adducts obtained at different temperatures using different acids (1 eq.) in $\mathrm{CH}_{2} \mathrm{Cl}_{2}$

\begin{tabular}{|c|c|c|c|c|c|}
\hline Entry & $T\left({ }^{\circ} \mathrm{C}\right)$ & $\begin{array}{l}\text { Reaction } \\
\text { time (h) }\end{array}$ & Acid & $\begin{array}{l}\text { Yield } \\
(\%)^{\mathrm{a}}\end{array}$ & $\begin{array}{c}2 / 3 / 4 \\
\text { Ratio }(\%)^{b, c}\end{array}$ \\
\hline 1 & \multirow{5}{*}{-78} & \multirow{5}{*}{5} & - & - & -/-/traces \\
\hline 2 & & & TFA & 26 & $32 / 15 / 53$ \\
\hline 3 & & & $\mathrm{BF}_{3}$ & 44 & $6 / 14 / 80$ \\
\hline 4 & & & $\mathrm{AlCl}_{3}$ & 32 & $0 / 42 / 58$ \\
\hline 5 & & & $\mathrm{ZnI}_{2}$ & 11 & $27 / 19 / 54$ \\
\hline 6 & \multirow{5}{*}{-12} & \multirow{5}{*}{5} & TFA & 65 & $25 / 13 / 62$ \\
\hline 7 & & & $\mathrm{BF}_{3}$ & 48 & $5 / 18 / 77$ \\
\hline 8 & & & $\mathrm{AlCl}_{3}$ & 29 & $0 / 38 / 62$ \\
\hline 9 & & & $\mathrm{ZnI}_{2}$ & 12 & $26 / 21 / 53$ \\
\hline 10 & & & $\mathrm{HClO}_{4}$ & 60 & $28 / 21 / 51$ \\
\hline 11 & \multirow{5}{*}{-20} & \multirow{5}{*}{48} & TFA & 46 & $18 / 14 / 68$ \\
\hline 12 & & & $\mathrm{BF}_{3}$ & 24 & $5 / 18 / 77$ \\
\hline 13 & & & $\mathrm{AlCl}_{3}$ & 10 & $0 / 40 / 60$ \\
\hline 14 & & & $\mathrm{ZnI}_{2}$ & 9 & $26 / 22 / 52$ \\
\hline 15 & & & $\mathrm{HClO}_{4}$ & 52 & $40 / 18 / 42$ \\
\hline
\end{tabular}

${ }^{a}$ Isolated yield after aqueous work-up and trituration with methanol and filtration through of celite/silica .

${ }^{\mathrm{b}}$ Adducts ratio was determinated by yield of pure, isolated compounds (flash chromatography), with recovery of oxime 1 .

${ }^{c}$ Adducts ratio was also determinated by GC (see supplementary data). 
In an attempt to explain the stereochemical outcome of the 1,3-dipolar and aza-Diels-Alder reactions, we present in Scheme 3 three models for the approach of diene/dienoplile and diene/1,3-dipole.
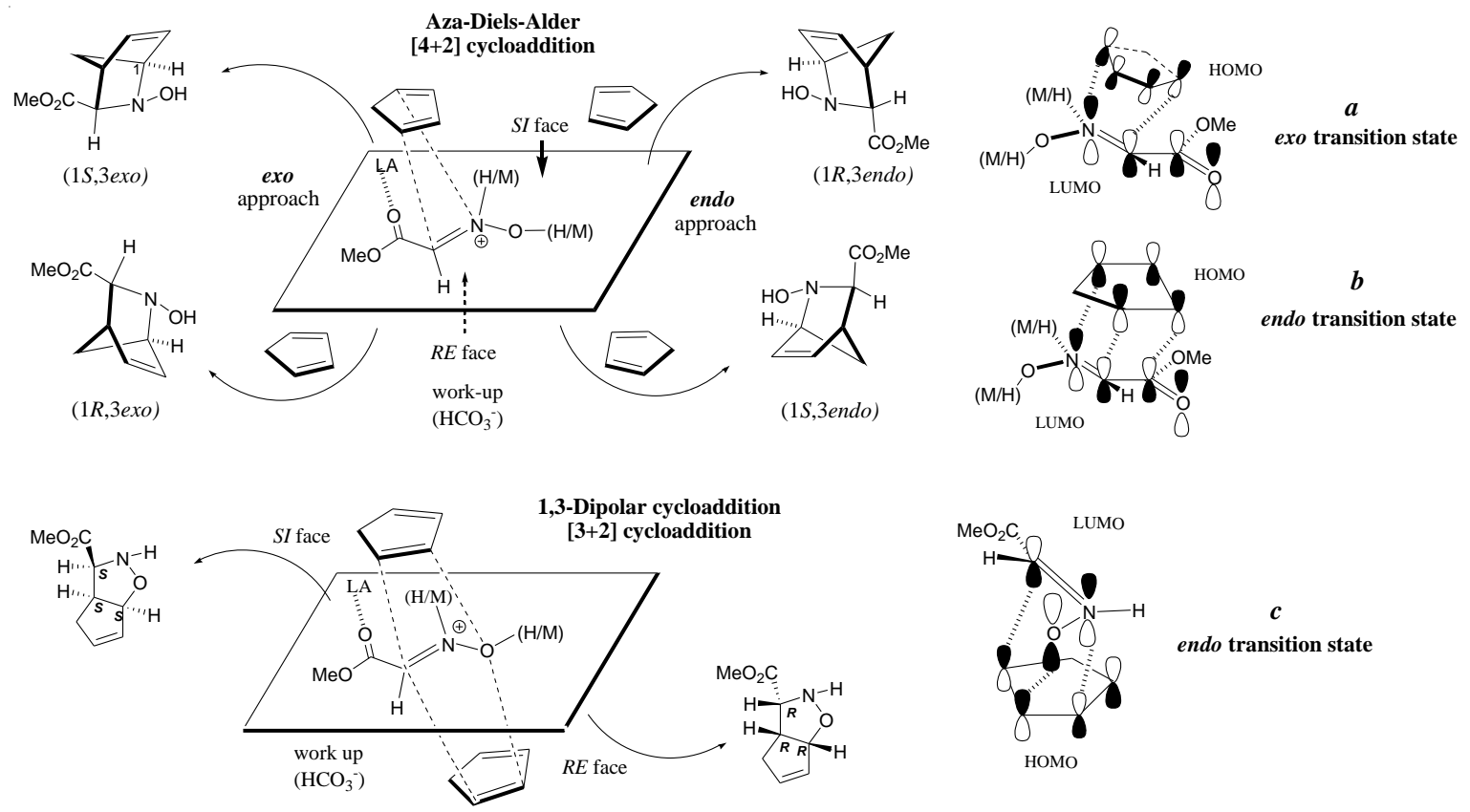

Scheme 3. The three possibilities of cycloaddition between oxime $\mathbf{1}$ and CPD. $\boldsymbol{a}$ - oxime $\mathbf{1}$ acts as a dienophile and CPD as diene, affording exo adduct; $b$ - oxime 1 acts as a dienophile and CPD as diene, affording endo adduct; $c$ - in this case, oxime $\mathbf{1}$ is the "four-electron component" and CPD acts as dipolarophile in the [3+2] cycloaddition reaction. After work up, deprotonation of the nitrogen atom takes place. Although in this scheme the catalyst $(\mathrm{H}$ or $\mathrm{M}=\mathrm{BF}_{3}, \mathrm{AlCl}_{3}$ and $\mathrm{ZnI}_{2}$ ) is arbitrarily coordinated to the nitrogen atom but there is the possibility of coordination to the oxygen atom.

The results described above are in general accord with the frontier molecular orbitals theory (FMO) of nitrone cycloadditions. 1,3-Dipolar cycloadditions, like the aza-Diels-Alder reaction, proceed through exo or endo transition states. ${ }^{10 \mathrm{~g}, \mathrm{~h}}$ The dominant primary interaction for the acidactivated cycloaddition of nitrone and cyclopentadiene involves the LUMO (dipole)-HOMO (dipolarophile) interaction.

The examination of the endo transition state of 1,3-dipolar cycloadditions reveals that the secondary orbital interactions between the methylene group of the diene and the ester group of the oxime (nitrone) are more important than the stereochemical interactions. Furthermore, in the close vicinity of the $\mathrm{C}=\mathrm{N}$ bond of the nitrone derivative, the oxygen group $\left(\mathrm{O}_{\mathrm{sp} 3 / \mathrm{sp} 2 \mathrm{p}}\right)$ exerts a larger steric hindrance than the $\left(\mathrm{C}_{\mathrm{sp} 2}\right)$-ester group, which favours this approach over its exo counterpart, thereby accounting for the formation of only racemic oxazabicycle 4 . The fact that 
yield of 4 increases in the presence of acids in the order $\mathrm{BF}_{3}>\mathrm{AlCl}_{3}>\mathrm{ZnI}_{2}>\mathrm{TFA}>\mathrm{HClO}_{4}($ see Table1), suggests two additional factors favouring the endo approach: i) the formation of an oxygen-metal complex and/or nitrogen-metal complex $[=\mathrm{N}(\mathrm{H}) \mathrm{O} \uplus \mathrm{A}]$ which increase the orbital coefficient of nitrogen in the LUMO, increasing the secondary orbital interaction; ii) the probable formation of an ester-metal complex increases the orbital coefficient of carbon (of the $\mathrm{C}=\mathrm{N}$ group) in the LUMO, increasing the primary orbital interaction.

In what concerns the aza-Diels-Alder reaction, it is more difficult to suggest a hypothesis but some plausible considerations may be taken into account to offer a rationale for the observed results:

* When Bronsted acids (TFA, $\mathrm{HClO}_{4}$ ) and $\mathrm{ZnI}_{2}$ (bulkier Lewis acid) were used as catalysts, the proportion of the exo-adduct was slightly superior than that of the endo one; This observation suggests that in the close vicinity of the $\mathrm{C}=\mathrm{N}$ bond of the nitrone derivative, the oxygen group $\left(\mathrm{O}_{\mathrm{sp} 3}: \mathrm{OH}\right.$ and $\mathrm{O}-\mathrm{Zn}$ complex $)$ exerts a larger steric hindrance than the $\left(\mathrm{C}_{\mathrm{sp} 2}\right)$-ester group. Consequently, in order to minimize stereochemical interaction in the transition state between the methylene group of the diene and the oxygen of the nitrone $(\mathrm{O}-\mathrm{N}=\mathrm{C})$, the exo approach dienedienophile must occur in more extension than the endo approach.

* When $\mathrm{BF}_{3}$ was used as Lewis acid, the endo/exo ratio of the adducts increased and with $\mathrm{AlCl}_{3}$ only endo-adduct was obtained. These facts suggest that formation of the nitrone-metal complex and ester-metal complex increases the orbital coefficients of nitrone in the LUMO, increasing the primary and secondary orbital interactions, respectively.

The configuration of the nitrogen atom in the final adduct is irrelevant, since it exists as a tertiary oxyamine, after workup, capable of undergoing inversion of the lone pair of electrons to achieve the most stable configuration.

\section{Conclusions}

In conclusion, we have shown that glyoxylate oximes can act either as dienophiles or as 1,3dipoles when reacting with 1,3-dienes, giving rise to the corresponding cycloadducts by independent concerted mechanisms. Both reactions occur by acid-mediated catalysis. According to the results obtained, the 1,3-dipolar cycloaddition seems to be kinetically more favourable. Further developments of the asymmetric cycloadditions between glyoxylate oximes and 1,3dienes are in progress in our laboratory. 


\section{Acknowledgements}

This work was supported by Centro de Investigação em Química of University of Porto. The authors thank the Fundação para a Ciência e Tecnologia $(F C T)$ for financial support of this work under project POCTI/QUI/44471/2002 (Pluri-annual and Programmatic Funding) and for the grant to C. A. D. Sousa (SFRH/BD/31526/2006).

\section{References and notes}

1. (a) Denis, N. Org. React. Mech. 2007, 427-467. (b) Battiste, M. A., Pelphrey, P. M., Wright, D. L., Chem. Eur. J. 2006, 12, 3438. (c) Ess, D. H., Jones, G. O., Houk, K. N., Adv. Synth. Catal. 2006, 348, 2337. (d) Domingo, L. R., Mini-Rev. Org. Chem. 2005, 2, 47.

2. (a) Kleemann, A., Engel, J., Kutscher, B. and Reischert, D. Pharmaceutical Substances: Synthesis, Patents, Applications, $3^{\text {rd }}$ ed.; Thieme: Würtsburg, Germany, 1999. (b) Tietze, L. F., Kettschau, G., Top. Curr. Chem. 1997, 189, 1-120. (c) Buonora, P., Olsen, J.-C. and Oh, T. Tetrahedron 2001, 57, 6099. (d) Heintzelman, G. R., Meigh, I. R., Mahajan, Y. R., Weinreb, S. M., Org. React. 2005, 65, 141. (e) Weinreb, S. M. Comprehensive Organic Synthesis; L. A. Paquette, Ed.; Pergamon Press: Oxford, 1991, Chapter 4.2.

3. (a) Timén, A. S. and Somfai, P. J. Org. Chem. 2003, 68, 9958; (b) Rodríguez-Borges, J. E., GarcíaMera, X., Fernández, F., Lopes, V. H. C., Magalhães, A. L., Cordeiro, M. N. D. S. Tetrahedron 2005, 61, 10951; (c) Fernández, F., García-Mera, X., Vale, M. L. C., Rodriguez-Borges, J. E. Synlett 2005, 2, 319; (d) Vale, M. L. C., L., Rodriguez-Borges, J. E., Caamaño, O., Fernández, F., García-Mera, X. Tetrahedron 2006, 62, 9475; (e) Bailey, P. D., Londesbrough, D. J., Hancox, T. C., Heffernan, J. D., Holmes, A. B. J. Chem. Soc., Chem. Commun. 1994, 2543; (f) Ekegren, J.K., Modin, S.A., Alonso, D.A., Andersson, P.G. Tetrahedron: Asymmetry 2002, 13, 447; (g) Abraham, H., Stella, L. Tetrahedron 1992, 48, 9707; (h) Szymanski, S., Chapuis, C., Jurczak, J., Tetrahedron: Asymmetry 2001, 12, 1939; (i) Bailey, P.D., Brown, G.R., Korber, F., Reed, A. and Wilson, R.D. Tetrahedron: Asymmetry 1991, 2, 1263; (j) Alves, C. N., da Silva, A. B. F., Marti, S., Moliner, V., Oliva, M. Andrés, J., Domingo, L. R. Tetrahedron 2002, 58, 2695; (k) Garcia, J. I., Martinez-Merino, V., Mayoral, J. A., Salvatelha, L. J. Am. Chem. Soc. 1998, 120, 2415.

4. (a) Jorgensen, K. A. Angew. Chem. Int. Ed. 2000, 39, 3558; (b) Badorrey, R., Cativiela, C., Díaz-deVillegas, M. D., Gálvez, J. A. Tetrahedron 1999, 55, 7601.

5. (a) Alves, M. J., Garcia-Mera, X., Vale, M. L. C., Santos, T. P., Aguiar, F. R., Rodriguez-Borges, J. E. Tetrahedron Letters 2006, 47, 7595. (b) J. E. Rodriguez-Borges, M. L. C. Vale, F. R. Aguiar, M. J. 
Alves, X. García-Mera, Synthesis 2008, 971-977, and references therein. (c) Maison, W. Eur. J. Org. Chem. 2007, 2276-2284, and references therein.

6. (a) Fleury, J. P., Desbois, M., See, J. Bull. Soc. Chim. Fr.1978, II-147. (b) Biehler, J. M., Fleury, J. P. J. Heterocycl. Chem. 1971, 8, 431. (c) Blondet, D., Morin, C. J. Chem. Soc.,Perkin Trans. 1 1984, 1085. (c) Dormagen, W., Rotscheidt, K., Breitmaier, E. Synthesis 1988, 636.

7. (a) Dewar, M. J. S., Olivella, S., Stewart, J. J. P. J. Am. Chem. Soc. 1986, 108, 5771. (b) Bernstein, Z., Ben-Ishai, D. Tetrahedron 1977, 33, 881.

8. (a) Ritson, D. G., Cox, R. J., Berge, J. Org. Biomol. Chem. 2004, 2, 1921. (b) Gonçalves, I. S., Santos, A. M., Romão, C. C., Lopes, A. D., Rodriguez-Borges, J. E., Pillinguer, M., Ferreira, P., Rocha, J., Kuhn, F. E., J. Organometallic Chem 2001, 626, 1.

9. (a) Crystallographic data for the structures in this paper, have been deposited at the Cambridge Crystallographic Data Centre as supplementary publication numbers CCDC6891 (compound 1), CCDC689192 (compound 3) and CCDC689200 (compound 5); (b) Analysis data of compounds: ( \pm )Methyl (1R,4R,5R)-(2-ox-3-azabicyclo[3.3.0]oct-7-ene)-4-carboxylate (4): ${ }^{1} \mathrm{H}$ NMR (300 MHz, $\left.\mathrm{CDCl}_{3}\right): 6.10-6.07(\mathrm{~m}, 1 \mathrm{H}, 8-\mathrm{H}), 5.62\left(\mathrm{dt}, J_{d}=8.1 \mathrm{~Hz}, J_{t}=2.2 \mathrm{~Hz}, 1 \mathrm{H}, 7-\mathrm{H}\right), 5.43(\mathrm{~d}, J=6.6 \mathrm{~Hz}, 1 \mathrm{H}$, 1-H), 5.38 (br s, $1 \mathrm{H}$, exch. $\left.\mathrm{D}_{2} \mathrm{O}, \mathrm{NH}\right), 4.00\left(\mathrm{dd}, J_{l}=12.4 \mathrm{~Hz}, J_{2}=8.4 \mathrm{~Hz}, 1 \mathrm{H}, 4-\mathrm{H}\right), 3.78(\mathrm{~s}, 3 \mathrm{H}$, OMe), $3.38\left(\mathrm{ddt}, J_{t}=8.4 \mathrm{~Hz}, J_{d l}=6.6 \mathrm{~Hz}, J_{d 2}=2.2 \mathrm{~Hz}, 1 \mathrm{H}, 5-\mathrm{H}\right), 2.49(\mathrm{dd}, J=18.2 \mathrm{~Hz}, J=8.1 \mathrm{~Hz}$, $\left.1 \mathrm{H}, 6_{\text {syn }}-\mathrm{H}\right), 2.09$ (dquint, $\left.J_{d}=18.2 \mathrm{~Hz}, J_{\text {quint }}=2.2 \mathrm{~Hz}, 1 \mathrm{H}, 6_{\text {ant }}-\mathrm{H}\right) ;{ }^{13} \mathrm{C} \mathrm{NMR}\left(75 \mathrm{MHz}, \mathrm{CDCl}_{3}\right): 169.8$ (COO), 137.7 (C8), 127.9 (C7), 91.9 (C1), 67.2 (C4), 52.0 (MeO), 45.9 (C5), 34.5 (C6); ESI-MS: calculated for $\left[\mathrm{C}_{8} \mathrm{H}_{11} \mathrm{NO}_{3}+\mathrm{H}\right]^{+}\left(M+\mathrm{H}^{+}\right)$170.18, found 170.47. Anal. calcd. for $\mathrm{C}_{8} \mathrm{H}_{11} \mathrm{NO}_{3}$ : C 56.80, H 6.55, N 8.28; found: C 56.75, H 6.59, N 8.25. ( \pm )-Methyl [(3-exo)-2-hydroxy-2azabicyclo[2.2.1]hept-5-ene]-3-carboxylate (2): ${ }^{1} \mathrm{H} \mathrm{NMR}\left(300 \mathrm{MHz}, \mathrm{CDCl}_{3}\right): 6.66$ (br s, $1 \mathrm{H}$, exch. $\left.\mathrm{D}_{2} \mathrm{O}, \mathrm{OH}\right), 6.68-6.64(\mathrm{~m}, 1 \mathrm{H}, 5-\mathrm{H}), 6.34(\mathrm{dd}, J=5.7 \mathrm{~Hz}, J=2.1 \mathrm{~Hz}, 1 \mathrm{H}, 6-\mathrm{H}), 4.29$ (br s, 1H, 1-H), 3.76 (s, 3H, OMe), 3.16 (br s, 1H, 4-H), 2.89 (d, J=2.1 Hz, 1H, $\left.3_{\text {endo }}-\mathrm{H}\right), 1.82$ (d, J = 9.3 Hz, $1 \mathrm{H}, 7_{\text {syn }}{ }^{-}$ $\mathrm{H}), 1.50\left(\mathrm{dd}, J=9.3 \mathrm{~Hz}, J=1.5 \mathrm{~Hz}, 1 \mathrm{H}, 7_{\text {anti }}-\mathrm{H}\right) .{ }^{13} \mathrm{C} \mathrm{NMR}\left(75 \mathrm{MHz}, \mathrm{CDCl}_{3}\right)$ : 172.9 (COO), 138.1 (C6), 133.1 (C5), 70.4 (C3), 69.5 (C4), 52.2 (C1), $\left.47.6\left(\mathrm{O}_{\mathrm{CH}}\right)_{3}\right) 45.2$ (C7); ESI-MS: calculated for $\left[\mathrm{C}_{8} \mathrm{H}_{11} \mathrm{NO}_{3}+\mathrm{H}\right]^{+}\left(M+\mathrm{H}^{+}\right)$170.18, found 170.53. Anal. calcd. for $\mathrm{C}_{8} \mathrm{H}_{11} \mathrm{NO}_{3}: \mathrm{C}$ 56.80, $\mathrm{H}$ 6.55, $\mathrm{N}$ 8.28; found: C 56.76, H 6.60, N 8.26. (土)-Methyl [(3-endo)-2-hydroxy-2-azabicyclo[2.2.1]hept-5-ene]-3carboxylate (3): M.p. $102-105{ }^{\circ} \mathrm{C}$; ${ }^{1} \mathrm{H}$ NMR $\left(300 \mathrm{MHz}, \mathrm{CDCl}_{3}\right.$ ): 8.13 (br s, $1 \mathrm{H}$, exch. $\left.\mathrm{D}_{2} \mathrm{O}, \mathrm{OH}\right), 6.24$ (br s, 2H, 5-H + 6-H), $4.11\left(\right.$ br s, 1H, 1-H), $3.76\left(\mathrm{~d}, J=3.6 \mathrm{~Hz}, 1 \mathrm{H}, 3_{\text {exo }}-\mathrm{H}\right.$ ), $3.66(\mathrm{~s}, 3 \mathrm{H}, \mathrm{OMe}), 3.33$ (br s, $1 \mathrm{H}, 4-\mathrm{H}), 2.22\left(\mathrm{~d}, J=8.7 \mathrm{~Hz}, 1 \mathrm{H}, 7_{\text {syn }}-\mathrm{H}\right), 1.74\left(\mathrm{~d}, J=8.7 \mathrm{~Hz}, 1 \mathrm{H}, 7_{\text {anti }}-\mathrm{H}\right) .{ }^{13} \mathrm{C}$ NMR $(75 \mathrm{MHz}$, $\mathrm{CDCl}_{3}$ ): 172.1 (COO), 139.5 (C5), 134.3 (C6), 72.9 (C1), 71.2 (C3), $51.9\left(\mathrm{OC}_{3}\right), 46.3$ (C7), 45.3 (C4); ESI-MS: calculated for $\left[\mathrm{C}_{8} \mathrm{H}_{11} \mathrm{NO}_{3}+\mathrm{H}\right]^{+}\left(M+\mathrm{H}^{+}\right)$170.18, found 170.67. Anal. calcd. for $\mathrm{C}_{8} \mathrm{H}_{11} \mathrm{NO}_{3}$ : C 56.80, H 6.55, N 8.28; found: C 56.77, H 6.57, N 8.26. ( \pm )-Methyl (1R,4R,5R)-[2-(3,5- 
dinitrobenzoyl)-2-ox-3-azabicyclo[3.3.0]oct-7-ene]-4-carboxylate (5): M.p. $60-62{ }^{\circ} \mathrm{C} ;{ }^{1} \mathrm{H}$ NMR $(300$ $\left.\mathrm{MHz} \mathrm{CDCl}_{3}\right): 9.16$ (t, $\left.J_{\text {meta }}=2.1 \mathrm{~Hz}, 1 \mathrm{H}, 4^{\prime}-\mathrm{H}\right), 9.07$ (d, $J_{\text {meta }}=2.1 \mathrm{~Hz}, 2 \mathrm{H}, 2^{\prime}-\mathrm{H}+$ 6' $\left.^{\prime}-\mathrm{H}\right), 6.21-6.17$ $(\mathrm{m}, 1 \mathrm{H}, 8-\mathrm{H}), 5.84\left(\mathrm{dt}, J_{d}=7.8 \mathrm{~Hz}, J_{t}=2.2 \mathrm{~Hz}, 1 \mathrm{H}, 7-\mathrm{H}\right), 5.28(\mathrm{dd}, J=6.7 \mathrm{~Hz}, J=1.8 \mathrm{~Hz}, 1 \mathrm{H}, 1-\mathrm{H})$, $5.22(\mathrm{~d}, J=9.9 \mathrm{~Hz}, 1 \mathrm{H}, 4-\mathrm{H}), 3.84(\mathrm{~s}, 3 \mathrm{H}, \mathrm{OMe}), 3.77-3.66(\mathrm{~m}, 1 \mathrm{H}, 5-\mathrm{H}), 2.67\left(\mathrm{ddt}, J_{t}=18.0 \mathrm{~Hz}, J_{d l}=\right.$ $\left.8.7 \mathrm{~Hz}, J_{d z}=2.2 \mathrm{~Hz}, 1 \mathrm{H}, 6_{s y n}-\mathrm{H}\right), 2.44\left(\mathrm{ddt}, J=18.0 \mathrm{~Hz}, J=2.4 \mathrm{~Hz}, J=2.2 \mathrm{~Hz}, 1 \mathrm{H}, 6_{\text {anti }}-\mathrm{H}\right)$. Anal. calcd. for $\mathrm{C}_{15} \mathrm{H}_{13} \mathrm{~N}_{3} \mathrm{O}_{8}$ : C 49.59, $\mathrm{H}$ 3.61, N 11.57; found: C 49.53, H 3.70, N 11.52. Methyl glyoxylate oxime (1): see supplementary data and reference $8 \mathrm{a}$.

10. (a) "Advances in Cycloaddition": Huisgen, R., "Steric Course and Mechanism of 1,3-Dipolar Cycloadditions", Dennis P. Curran, Ed., vol. 1, 1988; (b) Synthetic Applications of 1,3-Dipolar Cycloaddition Chemistry Toward Heterocycles and Natural Products, Eds.: A. Padwa, W. H. Pearson, John Wiley \& Sons, New York, 2002; (c) H. Pellissier, Tetrahedron 2007, 63, 3235; (d) K. V. Gothelf, K. A. Jorgensen, Chem. Rev. 1998, 98, 863; (e) M. Frederickson, Tetrahedron, 1997, 53, 403; (g) D. H. Ess, G. O. Jones, K. N. Houk, Adv. Synth. Catal. 2006, 348, 2337; (h) Padwa, A., Fisera, L., Koehler, K. F., Rodriguez, A., Wong, G. S. K. J. Org. Chem. 1984, 49, 276; (i) A. E. Koumbis, J. K. Gallos, Curr. Org. Chem. 2003, 7, 585; (j) Grigg, R. Chem. Soc. Rev. 1987, 16, 89; (k) P. Armstrong, R. Grigg, S. Surendrakumar, W. J. Warnock, J. Chem. Soc. Chem. Commun. 1987, 1327.

11.(a) Bailey, P. D., McDonald, I. M., Rosair, G. M., Taylor, D. J. Chem. Soc.,Chem. Commun. 2000, 2451. (b) Heesing, A., Herdering, W., Henkel, G., Krebs, B. Chem. Ber. 1983, 116, 1107.

12. (a) Gawley, R. E. Org. React. (N. Y.) 1988, 35, 1. (b) McCarty, C. G. "The Chemistry of the CarbonNitrogen Double Bond”, Patai, S., Ed., Interscience-New York 1970, 408. (c) Beckwith, A. L. J. “The Chemistry of Amides”, Zabicky, J., Ed., Interscience-N.ew York 1970, 131. 